\title{
DESCRIPTION OF THE ELECTRIC LIGHT ON THE ISLE OF MAY.
}

By Mr. DAVId A. STEVENSON, F.R.S.E., of Epinberah.

The Lighthouse situated on the Isle of May, at the mouth of the Firth of Forth, Plate 61, has recently been lighted with electricity; and as this light, besides being, the author believes, the most powerful in the world, possesses several novel features, he has the pleasure of offering the following notes regarding it, trusting that they will prove of interest in connection with the visit to be made to the lighthouse on the occasion of the present meeting.

Previous Lighting.-The Isle of May was originally lighted in 1636 with an open coal fire. In 1816 the Commissioners of Northern Lighthouses, having previously purchased the island with the right to levy tolls for the lighthouse, altered the light to argand lamps with silvered parabolic reflectors. In 1836 it was converted to the dioptric system, with a first-order fixed-light apparatus, and a fourwick burner; and on 1st December 1886 the electric light was substituted, and shown in connection with a dioptric condensing apparatus. For the last fifteen years the Commissioners of Northern Lighthouses, acting under the advice of their engineers, Messrs. Stevenson, had been anxious to establish an electric light on the Scottish coast; but it was not till 1883 that the Board of Trade were able to sanction the expenditure, and suggested its introduction at the Isle of May on the ground that "there was no more important station on the Scottish shores, whether considered as a landfall, as a light for the guidance of the extensive or important trade of the neighbouring coast, or as a light to lea 1 into the rufuge harbour of the Forth." 
Notwithstanding the difficult access and isolated position of the Isle of May, distant five miles from the Fife shore, which is the nearest land, as shown in Fig. 1, Plate 61, it was resolved to accept the view of the Board of Trade, and to introducc the electric light there. The necessary plans and specifications were accordingly prepared by Messrs. Stevenson ; and the works, begun in June 1885, were completed, and the new light installed by 1st December 1886 .

Site.--The existing establishmont, Fig. 2, Plate 61, consisted of a lighthouse tower with accommodation for three keepers, placed on the summit of the island; and the additional buildings which it was nccessary to provide were dwellings for three more keepers with their families, an engine house, boiler house, chimney stalk, workshop, coal store, \&c. It was decided to place the whole of the new buildings and machinery near the base of the island, and to lead the current up to the tower by conductors. This decision was arrived at, because it was considered that the fact of boing able to place the engines closc to the small natural fresh-water loch, situated 270 yards from the light and 175 fect bolow it, from which fresh water for feed and condensing purposes could be readily obtained, and also the saving which would bo effected by not having to convey the fuel to the top of the island or to pump up water, would compensate for the loss of energy, due to such a length of conductor; while the saving of the cost of carriage of the materials and machinery to the top of the island, and of piping and pumping machinery, would more than counterbalance the original cost of the conductors.

The buildings were constructed in a plain and substantial manner of fire-brick, built in Portland cement, and roofed with concrete and val-dc-travers, carried on rolled beams and buckled plates. This part of the work was executed in an expeditious and satisfactory manner by the contractors, Messrs. Stratton, Edinburgh, notwithstanding the difficulty of getting materials taken to and landed on the island.

Generators. - It was originally intended to use the Brush compound-wound Victoria dynamo, giving a continuous current, and supplying a single automatically fod arc-lamp with the 
positive carbon below. This system was selected as being at once cheaper, and as giving a stronger light-power for the engine-power applied, than the magneto-electric machines, which had hitherto been exclusively used with success in lighthouses. The placing of the positive carbon below was adopted in order that the strongest light might be thrown upwards, so as to be dealt with by the upper part of the dioptric apparatus, and thus be more effectively utilised. The Brush Company at once set to work to produce a lamp of the above description, giving, with a current of 100 ampères. and 70 volts, a light of 30,000 candle power in the horizontal line, steady and suitable for burning in a lighthouse. This unfortnnately they were unable to accomplish, even after numerous trials; and at last, as the buildings on the island were nearly completed and it became necessary at once to procure reliable apparatus, recourse was had to the more expensive alternate-current machines of $\mathrm{De}$ Meritens, which, though not so powerful, are admirably steady in working, and had given excellent results in several lighthouses and also at the South Foreland experiments.

The generators at the Isle of May are two of De Meritens' alternate-current magneto-electric machines of the $L$ type, and are of the largest size hitherto constructed, weighing about $4 \frac{1}{2}$ tons each. The induction arrangement of each machine consists of five sets of twelve permanent magnets, sixty in all; and each magnet is made up of eight steel plates. The armature, which makes 600 revolutions per minute, is $2 \mathrm{ft} .6$ ins. diameter, and is composed of five rings with 24 bobbins on each, arranged in groups of four in tension and six in quantity.

With the circuit open, each machine develops an electromotive force of 80 volts, measured at the distributor; and with the circuit closed through an arc, 40 volts. An average current of 220 ampères is developed, thus yielding an electrical energy of 8,800 watts, or $11.8 \mathrm{HP}$. in the external circuit. The five rings are so arranged that one-fifth, two-fifths, three-fifths, four-fifths, or the whole of the current of a machine can at pleasure be sent to the distributur for transmission to the lantern; and further, the two machines can be coupled, and the full current from both be employed. 
Engines.-The machines, Figs. 3 to 7 , Plates 62 and 63, are placed in the engine-room, bolted down to concrete foundations, and are driven through a countershaft by belting from the engines. These are a pair of horizontal surface-condensing steam-engines, each with two cylinders of 9 inches diameter and 18 inches stroke, making 140 revolutions per minute, and each indicating $17 \cdot 7$ HP. with 40 lbs. steam pressure above atmosphere and 11 lbs. vacuum. To provide against accident or failure of water-supply, they have been arranged so as to be capable of being worked either condensing or non-condensing. Either of them is sufficient to drive one machine, the other engine being idle; or the two can be used together for driving both machines in thick weather. The steam to both cylinders is regulated by an equilibrium throttle-valve, which is controlled by a high-speed governor, adjusted for the engine to run at the normal speed of 140 revolutions per minute. Single, in place of compound, engines were adopted, because they are less complicated and better suited for the less skilled attendance of ordinary lightkeepers. Probably also greater regularity in driving has thus been secured, which is of course a matter of the greatest importance in electric lighting, especially where, as in this case, there is only a single arc-lamp in the circuit forming the resistance. The result has been eminently satisfactory; and the engines, which were built by Messrs. Umpherston, of Leith, are a most excellent piece of work.

Boilers.-There are two steam boilers, of which only one is in use at a time, the other being spare. Each is $20 \mathrm{ft}$. long, and $5 \mathrm{ft} .6$ ins. diameter, with one furnace-flue $3 \mathrm{ft}$. diameter and $8 \mathrm{ft}$. long, having six cross Galloway water-tubes. The shells are of " best best" $\frac{3}{8}$-inch steel plates, with the longitudinal joints double-riveted; and they were tested up to $110 \mathrm{lbs}$. per square inch, the working pressure being $40 \mathrm{lbs}$. The feed is principally rain water collected from the roofs and the pavement of the court; but water can, if required, be taken from the small loch, which is also used for condensing purposes. The coal consumption is $1 \mathrm{cwt}$. per hour of lighting, which includes banking the fires during the day. 
Conductors. - The current generated in the engine-room is conveyed to the lantern by leads, which consist of copper rods of 25 millimetres or 1 inch diameter, covered with a double water-proof wrapper. This is the first time that copper rods have been used for conducting the current for lighthouse illumination. They are constructed in $14 \mathrm{ft}$. lengths, the joints being formed with a zigzag scarf screwed up tightly by gunmetal coupling-boxes having four bolts in each. They are carried by timber bearers, placed in a groove made for them in the side of a concrete wall running from the engineroom to the tower, Figs. 10 and 11, Plate 65. The total distance to the lantern is 880 feet. Several bends are introduced to allow for expansion and contraction due to changes of temperature. The loss in the leads was expected not to exceed one-sixth of the total energy generated; but it is considerably more than this, amounting to at least one-fifth. It is hoped however that an improvement will yet be made in this particular.

Lamps.-The lamps, of which there are three, one in use and two spare, are of the Serrin-Berjot type, with some modifications: notably the shunt or bye-pass, first introduced in the South Foreland experiments on the suggestion of Dr. Hopkinson, whereby a large percentage of the current goes direct to the lower carbon, and only an amount sufficient to regulate the carbons is passed through the lamp. This is a great improvement, and prevents injury to the lamp from heating. The weak point about it, in the lamps sent to the Isle of May, was that the contact between the lower carbonholder and the bye-pass, being necessarily a sliding contact, was effected by copper-wire brushes; and these were found to wear out rapidly. On the suggestion of Mr. Munro, the engineer in charge of the station, a simple form of mercury contact has been substituted, and works quite satisfactorily.

Carbons.-The carbons in use are 40 millimetres or $1 \cdot 6$ inch diameter; but if desired $50 \mathrm{~mm}$. or 2-inch carbons can be used when both machines are running. They are Siemens make, and have a core of soft pure graphite, which has the effect of causing 
them to burn with greater regularity and stcadiness than they otherwise would, and of preventing a crater from forming and remaining at one side. The rate of consumption of the $40 \mathrm{~mm}$. carbons is $1 \frac{1}{4}$ inch per hour, or 2 inches including waste. The power of the are is estimated at 12,000 to 16,000 candles, when one machine only is running.

Dioptric Apparatus. - The dioptric apparatus, Figs. 8 and 9 , Plates 64 and 65, which was manufactured from Messrs. Stevenson's designs by Messrs. Chance of Birmingham, is of a novel description, the condensing principle being carried further than in any apparatus previously constructed. This principle consists in darkening certain sectors by diverting the light from them, and throwing it into the adjoining sectors so as to reinforce their light. Thus the power of the light is increased in proporsion as the dark are is increased. The light gives four flashes in quick succession every half minute; and during the bright periods the effict of this concentration of the rays is that the light radiating naturally from the focus is increased in power 15 times in azimuth in addition to the vertical condensation, excepting of course the loss due to reflection and absorption. The apparatus which effects this result is a second-order fixed-light apparatus $\mathbf{F}$ of $1400 \mathrm{~mm}$. or 55 inches diameter, which operates on the rays in the vertical plane. Outside of this there is a revolving cage $\mathrm{C}$ of straight vertical prisms, extending the full height of the fixed apparatus, or $5 \frac{1}{2}$ feet, and composed of two panels on opposite sides of the centre, each operating in the horizontal plane on 180 degrees of the light coming from the fixed apparatus, in such a way as to condense the whole 180 degrees into four flashes of 3 degrees each, that is, 45 degrces into 3 degrees, with the proper intervals of darkness between them, Fig. 9. This cage of glasswork $\mathrm{C}$ is caused to make one complete revolution every minute round the fixed apparatus, thereby producing the characteristic of four flashes every half minute. The fixed-light apparatus is not of the ordinary Fresnel section, but has the refracting portion confined to an angle of 10 degrees, the upper and lower reflecting prisms being carried 
nearer to the focal plane. This design, although involving the loss of some light, facilitated the adoption of the late Mr. Thomas Stevenson's proposal of dipping lights in fog, so as to be able to direct the strongest part of the light to the horizon in clear weather, and in fog to a point only three to five miles distant. Such a change could be most easily produced by simply raising and lowering the level of the radiant in the apparatus; but there was a difficulty in doing so in an ordinary optical apparatus, inasmuch as, when the position of the radiant was altered, the rays from the reflecting prisms, above and below the refractor, would be sent in an opposite direction to those coming from the refractor. This form of the fixed-light apparatus was also specially necessary at the time the apparatus was designed, because it was then intended, as already mentioned, to use a continuous-current machine with the positive carbon below; and consequently the strongest part of the light would have been dealt with by the uppor reflecting prisms. By making the apparatus almost entirely of totally reflecting prisms, instead of refracting and reflecting combined, all the prisms act in the same way: so that by lowering the radiant the whole of the light from every part of the apparatus can be dipped simultaneously to any required extent, with the exception of a small piece in the centre, which is a refractor, and which will sond light to the horizon when the other part of the apparatus is dipped. In clear weather the three upper prisms send their light from $\frac{1}{2}$ degree above the horizon to 3 degrees below it; the rest of the upper prisms and all the lower ones send their light to the horizon; and the refracting portion from 3 degrees to 5 degrees below the horizon. The dipping of the light during fog has not yet been used; but as soon as the lightkeepers, who, with the exception of the engineer, were the ordinary keepers in the service and knew nothing of electric lighting, have biscome thoroughly familiar with their duties, it is intended to introduce it, and probably in the same way to employ a less powerful current, and say $25 \mathrm{~mm}$. or 1 -inch carbons in very clear weather; while both machines with $50 \mathrm{~mm}$. or 2 -inch carbons will be used in very thick weather. 
Lamp Changing and Revolving Arrangements. - Standing in the centre of the light-room is a circular case $A$, Plate $64,5 \mathrm{ft} .8$ ins. diameter and $5 \mathrm{ft} .4$ ins. high, formed of enst-iron pilasters filled in between with glazed doors. The top of this case carries the fixed-light apparatus F, as well as a steel roller-path $5 \mathrm{ft} .10$ ins. diameter, on which the carriage supporting the cage $\mathrm{C}$ of vertical prisms travels on twelve steel rollers. The top of the case also serves as the service table $\mathrm{S}$, on which the electric lamp $\mathrm{L}$ stands when in focus. Access to the interior of the apparatus and to the lamp is obtained from the inside of the case, through a trap in the top of it. Some diffieulty was experienced in devising a suitable system of readily substituting one lamp for another, when it may be desired to change them, or in the event of the one in focus going wrong. The difficulty arose from the necessity of keeping the spare lamp out of the apparatus entirely, so as to prevent its interfering with the light emanating from the lamp in use, as the light shows all round the horizon. The change is accomplished by means of an arrangement of rails, and three turntables or shunt-tables $T$, on which the lamps can be freely run, and which are placed on the service table $S$. One of these is in the centre of the apparatus; and one is on a trap door, working vertically in guides and counterbalanced, in the manner of a hoist, whereby a lamp can be lowered from the level of the top of the case to the floor of the light-room. Here the lamp is again received on rails, on which it can be conveniently run out of the case, to be re-carboned and adjusted. In this way a lamp can be raised from the floor of the light-room into the apparatus, the lamp in the focus withdrawn on to one of the turn-tables and the fresh lamp run into focus, and the original lamp shunted on to the hoist and lowered out of the apparatus, all in about eight seconds.

A three-wick paraffin oil-lamp is kept trimmed and ready for use, in case of a failure of the electric current; and it can be lighted and put in the focus in about thrce minutes.

Within the case, and placed at one side of it, is a train of whecl-work $W$, actuated by a weight with a fall of 60 foet down the centre of the tower. This machine drives the revolving cage $\mathrm{C}$ of vertical prisms by a shaft $H$ which passes up through the top of 
the case, with a pinion working in an internal wheel of $4 \mathrm{ft} .10 \frac{1}{2}$ ins. diameter secured to the carriage of the cage. This machine is carefully boxed in, to prevent the dust from the incandescent carbons finding its way into the bearings, whereby great trouble has been caused at various lighthouses lighted by electricity.

Power of Light.-The resulting beam of light from this apparatus is about 3 million candles when one machine is in use, and with both machines 6 millions; that is, about 300 and 600 times more powerful than the old fixed oil-light. When the three-wick oil-lamp is put in the focus of this apparatus, the emergent beam is more powerful than the old fixed oil-light with a four-wick lamp, which was 9,446 candles. The light has been picked up and recognised by sailors at forty and fifty miles off, by the flashes illuminating the clouds overhead, although the geographical range of the light is only 22 miles.

The engine-room is connected by telephone with the light-room; and the houses of the keepers are connected by air whistles or electric bells with either the light-room or the engine-room.

Men employed.-The establishment consists of an engineer, four keepers, and an occasional or auxiliary keeper. The engineer, who is responsible for the management of the station, does not take a regular watch, but visits the engine-room and light-room occasionally during the night. Two of the keepers attend to the light-room duty, and two have charge of the engines and boilers, relieving each other in regular watches. The auxiliary keeper does any odd duties, such as carting fuel \&c.; and in the event of any of the others being ill takes his place. Since the light was first exhibited, the machinery and electrical appliances have worked without a hitch, and recourse to the oil-lamp has been unnecessary. This is the more gratifying when it is remembered that, as already stated, the men in charge, with the exception of the engineer, were new to the work, and that the light was started at a period of the year when the time of lighting was longest, namely sixteen hours. 
Cost.-The new buildings, engines, electric machines, lamps \&c. have cost $£ 15,835$; and the buildings, lantern \&c., previously on the island, which have been utilised, may be valued at $£ 6,600$. Thus the total cost of the installation may be taken at $£ 22,435$; and the cost of maintenance will not exceed $£ 1,050$ per annum. These figures are very moderate, considering the great power of the light, and the isolated position of the lighthouse. To compare the cost of this installation with what it would have been if oil were the illuminant, there must be added to the above $£ 6,600$ for buildings a sum of $£ 2,925$ for the cost of the apparatus and machine \&c., making a total of $£ 9,525$, while the cost of maintenance would have been $£ 330$ per annum. Taking these figures, and adding to the maintenance $3 \frac{1}{2}$ per cent. on the original outlay, it is found that while the oil-light would cost $3 \cdot 49$ shillings per hour and $0 \cdot 00017$ penny per candle power per hour, the electric light costs $9 \cdot 66$ shillings per hour or $2 \frac{3}{4}$ times more, and 0.000038 penny per candle power, or less than one quarter of what the oil light would cost per candle power. This is taking the electric light power of one machine.

Surprise has frequently been expressed by masters of vessels, and by residents on the neighbouring shores who live in view of the Islo of May light, that this light, which is so extremely brilliant in clear weather as to cast shadows at a distance of ten and fifteen miles, is so cut down by fog that some oven go the length of believing the old oil-light was better in fog. All who have experience of the electric light are quite prepared for the first part of this statement; while the last, it need hardly be said, is a mistake, inasmuch as the electric arc has been proved both by experiment in natural and artificial fog, and also by observations on existing lighthou ses lighted by electricity, to be in all circumstances of weather the most penetrating. Every night at twelve o'clock the lightkeepers at St. Abb's Head, 22 miles distant, where there is a first-order flashing light and one of the most powerful oil lights in the service, observe the Isle of May light, while the keepers there also observe the St. Abb's Head light. The result of the last five months' observations is that the Isle of May light is seen one-third oftener from St. Abb's Head than the St. Abb's Head light is seen from the Isle of May. It is perfectly true however 
that the superiority which is so apparent in clear and rainy wcather is very much reduced in hazy weather, and practically disappears in very dense fog. Looking to this fact and to the large first cost and annual maintenance, the author feels that the conclusion arrived at by the Trinity House is sound, namely that electricity should be used only for important landfall lights.

If however the most powerful light is desired independently of cost, then the electric arc has no rival. And if the further expense is to be incurred of introducing bifurm, triform, quadriform, or even double quadriform lights, then the electric light is better adapted than any other illuminant, because, on account of its focal compactness and other properties, it can be so dealt with by suitably designed dioptric apparatus that the whole light evolved is effectnally utilised. This is not the case with the large gas or oil flames generally used in the multiform system, in which for this and other roasons a considerable loss of light is incurred. Moreover the coolness of the electric arc renders multiform lights really practicable; and this can hardly be said to be the case eithor with gas or with oil.

Hyper-yodiant Ayparatus.-In the author's opinion however it is only in very exceptional cases indeed that electricity should be used; and he considers that a single oil or gas burner placed in the focus of a proportionately sized dioptric apparatus is sufficient for the generality of cases; and that any additional outlay which can be permitted should be expended in establishing a powerful sound signal to be used during fog when the light is obseured, and when for all practical purposes even the electric light itself would also be obscured. This is specially the case since the introduction, on Messrs. Stevenson's suggestion, of hyper-radiant apparatus suited for use with burners of large diameter. $\Lambda \mathrm{s}$ the result of experiments made in Edinburgh in 1869 they pointed out that the effectiveness of tho large Wigham burner was to a great extent lost in revolving apparatus, because much of the light was ex-focal. A year or two ago, when the Commissioners of Northern Lighthouses resolved to increase the size of the burners in some of their lights, an experimental lens of $1,330 \mathrm{~mm}$. or $52_{\mathrm{s}}^{3}$ inches focal distance, designed by thcir enginecrs, 
was constructed by Messrs. Barbier and Fenestre, and by the courtesy of the Trinity House was fully experimented upon at the South Foreland, on the termination of the experiments conducted there with electricity, gas, and oil. From experiments made by Sir James Douglass and the author, and from photometric observations by Mr. Harold Dixon, the expectations of Messrs. Stevenson were fully borne out, and the following conclusions seem warranted:that a single burner, shown in a complete panel of a revolving apparatus of the hyper-radiant kind, would give a more powerful light than burners and ordinary Fresnel lenses, arranged as biform, and would be of equal power to triform; while the consumption of oil or gas would be one-half or one-third respectively. Moreover all the disadvantages of superposed lenses, including excessive heat in the lightroom, diffeculty in the management of the burners, and obstruction of light by the necessary ventilating tubes, would be avoided.

The result of the above experiments has so conclusively established the advantages of the hyper-radiant apparatus that the American Lighthouse Board have since ordered a complete apparatus of this kind; while the Trinity House and the Irish Lighthouse Board have adopted this size of lens in lights recently ordered by them on Mr. Wigham's biform principle.

\section{Discussion.}

Sir James N. Dotglass, Member of Council, considered the subject of the present paper was one of the most important that could possibly engage the attention of mechanieal engineers. The establishment of good coast guides concerned not only the professional mariner but society generally; and perhaps the full importance of the subject was only realised when ships were caught in dangerous seas with imperfect coast signals, and when it became 
doubtful whether they would ever reach their destined port. He thanked the author most heartily for having brought this subject before the Institution, and for having offered the Members an opportunity, which so seldom occurred, of seeing a lighthouse in the latest state of scientific development, especially in so important a Jocality as the Firth of Forth, and on a site from which originally had been sent the light of an open coal fire. All who visited the lighthouse in the excursion arranged to the Isle of May would he was sure enjoy a great treat.

The subject of coast lighting was one that was unfortunately not generally understood; and it was very desirable that mechanical engineers at any rate should realise its importance, because what was at present wanted was a cheap electric light. After an experience of nearly thirty years of electric lighting, he agreed with the author that, in consequence of the high cost of installation and maintenance, the electric light was at present restricted to those of the most important positions where the large expenditure of money could be incurred by the responsible authority. It was stated in the paper (page 356) that the Isle of May light would cost per hour $2 \frac{3}{4}$ times more than an oil light. But how were the public generally to be assured that the greater cost was being beneficially utilised? especially when sailors so often declared that the electric light dazzled them in clear weather. The problem was now being solved with the electric and other lights by giving just sufficient light in clear weather, and as much as possible in thick weather; but still with the electric light this involved the larger relative cost, nearly as stated in the paper. The relative value of oil, gas, and electricity for lighthouse purposes was a question which had received the earnest consideration of the lighthouse authorities of this country ever since the first starting of the electric light in December 1858 at the South Foreland by Faraday and Holmes, whose names should never be forgotten in connection with the electric light and the production of the first practical dynamo for coast lighting. At that time an are light was obtained of abont 700 candle-power, while the first-order light whether of oil or of gas did not exceed 230 candles: so that the intensity of the electric light 
(Sir James N. Douglass.)

was at once treble that of oil or gas, and it thus became a formidable competitor at eea, as it had been in every direction on land. That result stimulated many improvements in coast lighting; and the consequence had been that at the present time with oil or gas about forty times the intensity or energy could be placed in the focus of optical apparatus for the service of mariners that had been possible at the date of starting the electric light. In order therefore to compete with gas and oil, an electric light was now required much more powerful than formerly; and this was provided for at the present time when an electric light of 30,000 or 40,000 candles was available in single focus. There appeared indeed to be no limit to the iutensity of light which by means of electricity could be provided for the benefit of the mariner, if only the funds could be obtained; but unfortunately for this important work, as for many others, money was scarce, and it was necessary to go on as cconomically as possible whilst the morcantile marine continued in its present depressed state. Moreover mariners appeared to agree that oil and gas at their present maximum intensity wore sufficient for ordinary purposes; therefore what appeared to be required was an electric light for specially important positions, of higher available maximum intensity than oil or gas, but not greatly exceeding the cost of installation or annual maintenance of these illuminants. If the cost of electricity could thus be reduced, there would doubtless be a very large field for it; and it was therefore a tompting opportunity for mechanical engineers in the present depressed state of trade to endeavour to produce a cheap electric light for lighthouse purposes.

With regard to the optical work, he should have preferred a single apparatus for both vertical and horizontal condensation and distribution of the light. He knew that the late Mr. Thomas Stevenson was never satisfied with the use of two apparatus, where one could be designed to do the work; and he had hoped that with his well known talents in optical engineering he would have succeeded in this rather difficult case. It was doubtless a very beautiful apparatus, and one which it would be difficult to surpass for the purpose. The optical treatment of the are light was an important matter for the consideration of electricians and engineers. 
It appeared that the apparatus described in the paper had first been designed for use with a continuous current; but in consequence of failure to obtain a suitable lamp for this current, the alternatecurrent machines and lamp of De Meritens as used at the late South Foreland experiments bad been adopted. These were found to be very reliable and efficient machines for lighthouse work, and the only known objection to them was their high price. One had been in nightly use for seven years at the Lizard, and the whole cost of repair during that period had been very trifling. With a continuous current there was formed at the carbons a single crater, which with the usual arrangement was formed at the point of the upper or positive carbon, as shown in Figs. 12 and 13, Plate 66. For the Isle of May light the position of the carbons was intended to be reversed, the positive carbon with its crater being placed below, with a view of radiating the most intense light upwards; and the dioptric apparatus was beautifully designed for utilising the light most effectively. In consequence of the failure of the continuous-current lamp, it had been necessary to resort to a machine and lamp giving alternating currents. The two carbons were then pointed nearly equally, as shown in Figs. 14 and 15, thus giving a more efficient radiant for utilising optically. Alternating currents therefore appeared to him to be the most perfect for lighthouse illumination.

For some time past his attention had been directed to the improvement of the carbons; because whether alternating or continuous currents were used, there was still the objectionable crater, which had the effect of locking up the most intense portion of the light generated, and preventing the most efficient optical disposal. This subject was exceedingly interesting. The improvement of large carbons by Messrs. Siemens, in providing them with a soft graphite core, had been very important and efficient in holding the are central and more steady than previously; but in spite of this there occurred the formation of the craters and sudden outbursts of the are in different directions all round the points, notwithstanding that the carbons themselves were kept perfectly in line. Wherever there was an ontburst of the are there was a maximum intensity of light in that direction, and unfortunately 
(Sir James N. Douglass.)

on the opposite side of the points there was at the same time a minimum intensity. These irregularities were very troublesome to deal with. The optical refinements described in the paper were intended for prodncing at half-minute periods four flashes in quick succession; these flashes were required to be of equal intensity and duration; but how was this to be done with such an unsteady arc as resulted from these irregular outbursts? His own idea was to make the carbons fluted, as shown in Figs. 16 to 19, Plate 66 ; and he was glad to say that this simple expedient had entirely fulfilled his expectations. For some time past he had been experimenting with fluted carbons up to 50 and 60 millimetres diameter $(2 \cdot 0$ and $2 \cdot 4$ inches), and they had worked with the arc nearly as steady as a candle flame, with an intensity of about 40,000 candles; and he was of opinion that carbons of this description could be used in producing a steady are light up to an intensity of a million candles. With these fluted carbons he found that good points were maintained without the formation of a crater; and thus the arc was maintained perfectly central, and the irregularities of the light with cylindrical carbons, due to their crater, were avoided. Carbons of this form wore now being manufactured by several firms. Some little difficulties were experienced at first; but when the tools were properly propared, it was found that the manufacture was as simple as with the cylindrical carbons. Another important advantage of the fluted carbons was that they were baked more uniformly and with less internal fracture.

Mr. Arthur Paget, Vice-President, hoped that, inasmuch as in the present case an open coal fire had been ultimately replaced by the electric light, the author would be able to state, approximately at all events, the cost per candle-power of the coal when burnt direct in an open fire as in 1636 , and the comparative cost at the present time, when, thanks to science and mechanical engineering, the coal was transmuted into light by the agencies of stcam and electricity. Iontion had been made by Sir James Douglass of a complaint made by the sailors that the electric light was now too strong when the ship was near the lighthouse: this appeared to mean that a light was 
asked for which would give less light near than far off. Instead of trying to solve so difficult a problem, would it not be more simple to educate the sailors not to look at the light too long when they wero close to it?

The appeal made by Sir James Douglass to mechanical engineers, to produce an electric light which would be cheap enough to justify the expenditure of public money upon it, was one which he could not reconcile with the statement in the paper (page 356) that the cost of the electric light at the Isle of May was only 0.000038 penny per candle-power per hour, or less than one quarter of what the oil light would cost. In view of this statement, he could not understand how it was more expensive to supply electric lighting than oil lighting.

Another point which also puzzled him was that in page 350 it was stated that "single in place of compound engines were adopted"; and in the next sentence it was stated that "probably greater regularity in driving has thus been secured." This opinion be thought would not be shared by those who were conversant with compound engines.

Mention was made on page 351 of a simple form of mercury contact, which had been substituted for a sliding contact, and was working quite satisfactorily. He wished to ask whether that was the ordinary form of mercurial contact generally used, or whether there were any special features in it, and if so what they were; because he understood that Sir James Douglass had for some time used for his lights a form of mercurial contact which was quite satisfactory.

Mr. WiLliam Geipel mentioned that experiments had lately been carried out by the Brush Corporation with a view to obtaining a lamp which wonld burn the positive carbon below. The difficulty was that the flame of the are was apt to fly away from the positive carbon when underneath; whereas when the positive carbon was above, the flame was held round it in suspension and assisted materially in reducing the resistance of the arc. The flame flying away from the arc caused heavy variations in the resistance, whereas the mode first experimented upon by the Brush Corporation of 
(Mr. William Geipel.)

controlling the arc was compatible with only a very small variation. The carbons had always previously been burnt the other way up, with the positive carbon above. Since these trials however, a better result had now been obtained by resorting to a more active regulation which was not quite so sensitive, but which at the same time answered the purpose very well. It was simply the old form of the Serrin lamp slightly modified, which gave great satisfaction notwithstanding the positive carbon being underneath.

As to the resistance of the conductors, which was stated in page 351 to amount to at least one-fifth of the total energy gencrated, he calculated that it should not be more than half as much. The loss of power to the extent of one-fifth, or 20 per cent., might be attributable to two causes : first to the low conductivity of the copper; and secondly to the joints, which occurred at intervals of only 14 feet. Those joints necessarily introduced a serious resistance, however tightly they might be screwed up; and he conld not see the object of resorting to a number of rods so coupled, instead of using one continuous cable such as was ordinarily employed in electric lighting. The cable might be insulated or not. An ordinary insulated cable could well rest on the wooden supports which were here used for carrying the stiff copper rods.

Another point, already referred to by Mr. Paget, was the opinion expressed in page 350 that probably greater regularity in driving was secured with a simple engine than would have beep obtained with a compound. For the electric light at the Lyceum Theatre in Edinburgh he had recently put up a small compound engine, indicating from 20 to 30 horse-power, and using $4 \mathrm{lbs}$. of common coal per horse-power per hour, which did not vary more than 15 revolutions in 800 of the dynamo, being less than 2 per cent. A simple engine he thought would not govern with any greater sensitiveness than that.

Mr. Alan Brebner said that, although the De Meritens alternatecurrent electro-magnetic machines were more expensive and less powerful than the continuous-current dynamo, his own experience was that they were found to be the safest and most reliable. As 
regarded the lamp constructed by the Anglo-American Brush Company for utilising the continuous current from one of their Victoria No. 2 dynamos, it proved after about a year's experimenting to be a complete failure. It was desired to burn the positive carbon below, in order that the light from the crater might be thrown upon the upper prisms of the optical apparatus, the most important part of which was above the horizontal axis. He had had an opportunity of testing the lamp at the South Foreland, and on the first trial a certain portion of the metal work was fused and burst into brilliant flame; on the next trial the brushes on the machine became red hot; and thus the matter ended, as time for further experimenting could not be given. As compared with a compound engine for lighthouse purposes, his own impression was that the simple engine was the best and the safest, and the most regular in its action; and the saving of fuel on such a small engine was really not worth considering, especially when put in the balance against certainty of action.

Mr. Wilson Hartnell considered that the problem of providing an electric light on a small scale, not much greater than the present oil lamps and at a moderate cost, had been solved already, and solved effectually. Turning to the cost of the light described in the paper, it would be seen that a very large sum had been spent --more than $£ 15,000$. Of this amount the engines, dynamos, and lamps he should think would form but a very small fraction. Why in putting down an electric light it should be thought necessary to have so many more persons in charge, he could not understand, except on the supposition that very little confidence was as yet felt in the electric light. For lighthouses it appeared to him that the best practice had not jet been attained in regard to electric lighting. The De Meritens machine was no doubt an excellent one, and he had nothing to say against it; it had been a good machine some years ago, but there were now many works capable of constructing dynamos which would give equal results at much less cost. Comparing the cost per candle-power as given in page 356 with that of the electric plants supplied to the admiralty, it seemed very 
(Mr. Wilson Hartnell.)

great. The engine here supplied might no doubt be a good simple engine, but compound engines could now be produced which were perfectly trustworthy and governing excellently. The whole plan described in the paper struck him as being good at the date it was planned, two years ago; but it was now distinctly behind the time, and he certainly thought that the engine and the whole of the electric-light apparatus were neither the best nor the cheapest, and by no means represented what might have been done. Naturally enough, large public bodies like the various Lighthouse Boards would not dare to take up what they considered the latest practice, without feeling that they incurred a grave responsibility; they preferred to go slowly forward, and to be, as they thought, very safc. But the trustworthiness of electric arc-lamps had now been abundantly proved; and if the authorities would have applied to any of the principal electrical engineers in this country, they might readily have obtained tenders for the whole of the electrical plant at a cost far below that given in the paper, and the engineers supplying the work would have been willing to take the whole responsibility of its success for a period of one or two years. So that the problem of smaller cost was really settled already.

Professor RYan enquired, with regard to the choice of the dynamo in the present instance, whether the competition between the De Meritens and the Brush machine had here been on equal terms; and wherein exactly it was that the Brush Co. had failed in the endeavour mentioned on page 3.19 to produce a lamp giving, with a current of 100 ampères at 70 volts, a light of 30,000 candle-power. Did the alleged inability to accomplish this object, even after numerous trials, refer to the production of any kind of lamp of that efficiency, or only of a lamp which should be steady and suitable for a lighthouse? It was in regard to steadiness and reliability he imagined that the Brush lamp failed to meet the requirements of the case. It was satisfactory at any rate to know that electrical engineers had had a chance given them of superseding the old form of machine; at the same time it was rather disappointing to learn that the old form of machine had not been superseded here. The 
lamp efficiency however, required of the Brush Co, amounting to nearly $4 \cdot 3$ candles per watt, was much higher than that which was finally accepted. The candle-power actually given by the present lamp was stated on page 352 to vary from 12,000 to 16,000 ; taking the latter as the highest candle-power recorded, and dividing it by the $11 \cdot 8$ horse-power or 8,800 watts given in page 349 , the result was only 1,356 candles per horse-power, less than 2 candles per watt; or, taking account of one-fifth loss in leads (page 351 ), about $2 \cdot 3$ candles per watt. It seemed hardly consistent that the Brush Co. should have been hampered by so much higher a standard of efficiency; and he wished to ascertain what was considered to be the precise nature of their failure.

Mr. Jeremian Head, Past-President, having occasionally been at sea, had always regardel lighthouses in relation to sea traffic in the light of signal-posts in relation to railway traffic, and he considered them as of equal importance. In clear weather he thought that the main interest of any important light was before it could be fully seen: when indeed the first glimmer began to be visible, and when every one was looking out for it. In the present paper therefore he had been particularly struck by the fact that the lenses were so arranged that they did not all send their light direct to the horizon, but some deflected it rather upwards and some rather downwards. It was evident that in clear weather those rays which were directed above and below the horizon would ultimately go respectively against the sky and against the sea, and would then be reflected again and again. To this reflection was due the glimmer seen from a long way off, before the light itself became directly visible. As to any reserve power or expense being directed to fog signals, that was evidently of the greatest possible importance. It had been recognised in ancient times when open fires were used; for there was at the same time the bell rock with its warning to mariners in case of fog. Whether all lighthouses now had sound signals he was not aware; if they had not, he thought they ought to have them. The disaster which had recently occurred to the Victoria steamer when off the French coast near Dieppe showed the importance of 
(Mr. Jeremiah Head.)

fog signals being maintained ready to be put in action the moment a fog appeared.

As to the use of compound engines, it had occurred to him, as to others, that in a place like an island with a lighthouse on it, where all the fuel had to be conveyed at a considerable expense, no arrangement could bo regarded as permanent which did not include the means of utilising the fuel as economically as possible. A single condensing engine therefore, working with a comparatively low steam-pressure, could hardly be considercd a permanent arrangement. In regard to regularity of motion, he could not but think that a good compound engine with high-pressure steam must be as advantageous in regularity of motion as it was in economy of fuel; this therefore seemed to him to be the form of steam-engine that must ultimately be used under such circumstances. As to greater complication and possible break-down, it had been contended, and very justly, that a properly mado compond engine was not more liable to break down than any other. But even supposing it were so, it would be seen that the engines described in the paper were so arranged that a single one of the pair was competent to do the work in case of need; and a compound engine, by introducing the boiler steam direct into the low-pressure cylinder in the event of a break-down of the high-pressure one, could also be made to work, though of course with less than the full economy. There was such a thing however, he thought, as over-providing against casualties. It was stated in page 354 of the paper that there was an oil-lamp kept trimmed and ready for use, which could be lighted and put into the focus in three minutes. Would it not be better to use this oil-lamp as a final resonree in case of trouble or break-down of any kind, rather than have so costly an intermediate resource as duplicate engines? And then would it not also be better to have a compound engine of the best kind and working in the best way, and to employ it for the regular work under ordinary circumstances? and if anything happened to the engine, would not the best thing be simply to substitute temporarily the oil-lamp, having it all ready and a sufficient store of oil to keep it alight until the engine could be repaired and the electric light got to work again? 
Mr. Sydney F. Walker considered that, if the conditions were made equal for oil lighting and electric lighting, there would be no difficulty in providing electric lights for lighthouses at the same cost as oil lights or even less. According to his own experience, the introduction of electricity lad always been at first more expensive; but as the use of it had continued, the expense had come to be considerably less, in regard both to first cost and to working cost, than that of the apparatus which it superseded. Thus far electric lighting had always had to meet the difficulty that those who used it were never satisfied; they always wanted more. In the case of the old oil lamp, or gas, or even the Davy lamp in the pit, the users had been satisfied with anything from one-tenth of a candle up to 300 candles; but no sooner was electric lighting spoken of than they wanted almost an unlimited amount of light, and they would not go into electric lighting unless they could get it not only at the sume cost as with the old apparatus, but also a great deal more powerful at the same cost. The problem to be dealt with did not depend upon the dynamo machine; as himself a dynamo manufacturer he was able to say that there was no difficulty in turning out a machine which would produce any current up to 1000 ampères under whatsoever conditions might be imposed. But the difficulty lay in constructing a lamp to utilise the current; and this was where he gathered from the paper that the Brush Company had found their difficulty, hampered especially as they were by having to put the positive carbon underneath. He questioned whether a shunt-wound dynamo was the most suitable for the work, owing to the great reduction in the electro-motive force when the external resistance was reduced, as for instance when the carbons were in contact. If more time had been allowed, he expected the problem might have been solved; indeed be understood that it had been solved already.

It was gratifying to see that the transmission of energy by electrical conductors had here been so fully recognised. Instead of the engines and boilers and dynamo being brought alongside the light, they were put at a place whore it was most convenient, and the current was conveyed to the lamp by moans of conductors. It 
(Mr. Sydney F. Walker.)

had been constantly objected to electric power, that it could not be transmitted economically. The present instance however was at any rate a recognition of the progress which had already been made in the transmission of power by electricity. The progress had perhaps been slow, but there had certainly been a distinct step in advance. He wished to ask why the conductors had been made of jointed copper rods. That appeared to him to be a singularly bad arrangcment; because it was always found in practice that the measured resistance exceeded the calculated resistance, and a margin was always allowed in an estimate, the principal reason being that it was impossible correctly to estimate what the resistance of the joints was going to be. A joint could not be made homogeneous, like a rod or other continuous conductor, and it was therefore desirable to have as few joints as possible: instead of which there appeared in this case to be an unnecessarily large number of joints. Not only wero joints a source of resistance in the first instance, but they.were possible sources of failure afterwards: they got dirty and led to all sorts of trouble.

With regard to carbons, he wished to ask whether any experiments had been made in measuring the amount of light with a given current and a variable size of carbon. In his own practice he had found that, with a given current, the larger the carbon up to a certain point the greater was the amount of light.

He desired to thank the author for having offered them the opportunity of seeing the apparatus described in the paper, and for t'ic careful account he had given of the employment of large currents ia arc lamps, of which few electrical engineers had had any experience.

Mr. David A. Stevenson said that in place of two agents (page 360) a singlo agent might of course have been employed; but that plan would have added considerably to the expense, and he did not think the result would have been so good.

The reason why it was desired to place the positive carbon below was because with a continuous-current machine the best part of the 
light would be thrown on the upper portion of the dioptric apparatus, where it could have been utilised to greater advantage.

The De Meritens machine, he agreed with Sir James Douglass, was an excellent one. During the past six months it had not given the slightest trouble, nothing having gone wrong with it. The only reason for wishing to use the Brush machine had been that it was expected to get a much stronger light from it.

For the simple form of mercury contact used at the Isle of May he was indebted to Mr. Munro. It was not in use at the South Foreland or elsewhere.

With reference to the conductors, it was true they were not so continuous as cables would have been; but the copper rods were employed on the recommendation of Professor Grylls Adams, than whom there could not have been a better authority.

In no way had the Brush Company been restricted in regard to the lamp. They undertook to produce a lamp of the kind desired, and they did their very best; but they found it impossible to accomplish the object after a year's experiments, and gave it up.

With all deference to the opinions expressed regarding the engines employed, he still thought that the simple engines for such a place as the Isle of May were the best to put into the hands of men who were not engineers; while from the economical point of view it should be borne in mind that the engines were small, only 16 horse-power, and in such a case he thought the saving by the use of compound engines was imaginary; and he was inclined to think that the Members would be of the same opinion when they had visited the place.

Ho was sorry he had no information for enabling the cost per candle-power of the old coal fire (page 362 ) to be compared with that of the electric light. The statement made by Sir James Douglass as to the great cost of electric lights was quite consistent with the remarks in the paper; for although the cost per candle-power of the electric light was so small, yet it was impossible to have an electric light except at a much greater cost than oil.

It was also impossible to work the electric light without a larger staff than an oil light (page 365), because it was necessary to have two 
(Mr. David A. Stevenson.)

men on duty constantly, whereas an oil light required only one. As to going slowly forward, lighthouse authorities had been and still were the pioneers in all lighting matters, and specially as regarded electricity. All the principal electric-light companies had been applied to when the Isle of May installation was planned, and at first they saw no difficulty in providing what was wanted, namely a single continuous-current powerful are-light, capable of being maintained for several hours consecutively. This however they had nltimately found it impossible to accomplish, and he could not learn that the problem had been solved yet. The Isle of May installation could therefore hardly be said to be out of date at present.

The President noticed it was stated in page 356 that the lightkeepers at St. Abb's Head perceived the light at the Isle of May, and vice versâ. He wished to ask whether there was any telegraphic communication between the two lighthouses, so that they could communicate every night what their observations were.

Mr. Stevenson said there was not; but the observations were made simultaneously, and monthly returns of them were sent to the Northern Lighthouse office.

The President had much pleasure in proposing a voto of thanks to Mr. Stevenson for his interesting paper, which had led to a very valuable discussion. Those who were about to visit the Isle of May lighthouse would be very glad to have heard this paper, because they now knew something of what they were going to see. 


\section{ELECTRIC LIGHTHOUSE. Plate 61.}

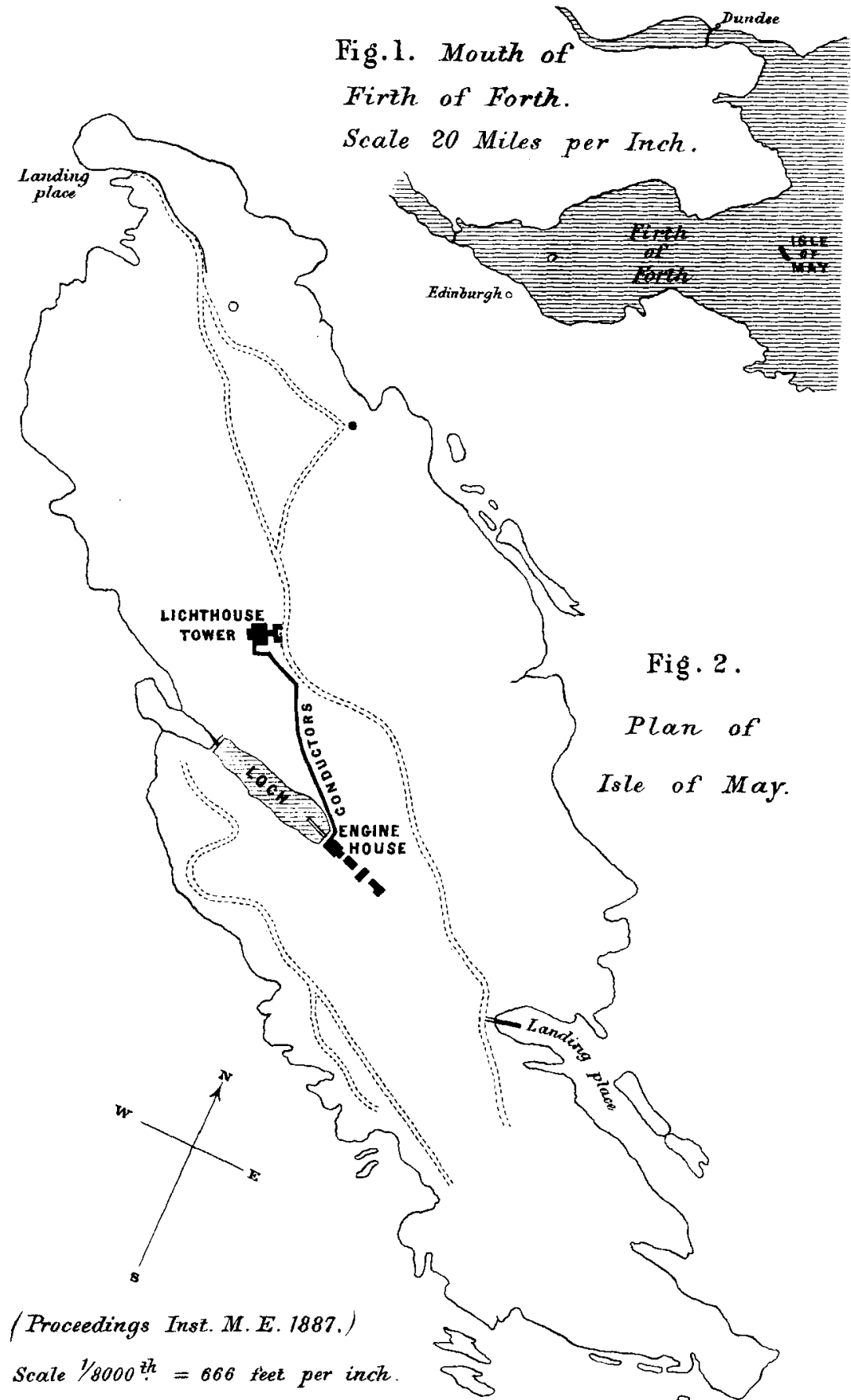




\section{ELECTRIC LIGHTHOUSE. Plate 6?.}

Engine and Boiler House \&o.

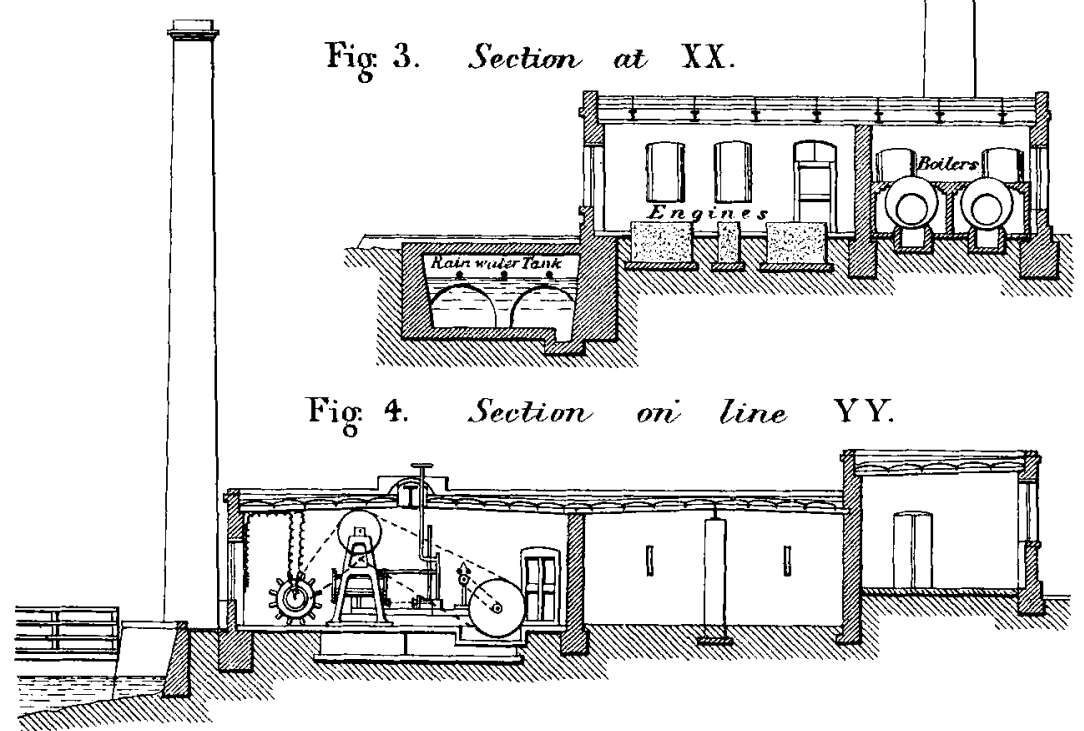

Fig: 3. Section at XX.

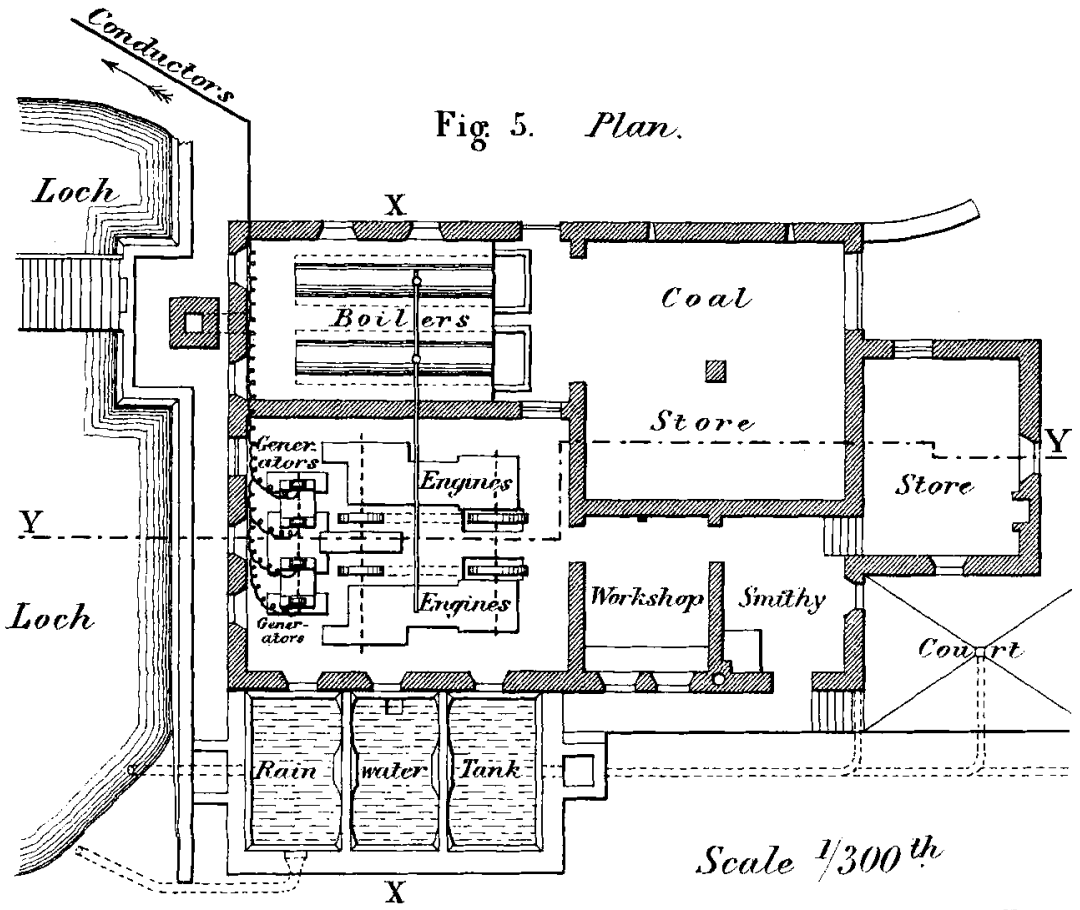

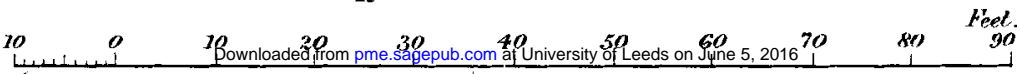




\section{ELECTRIC LIGHTHOUSE. Plate63.}

Engines and Marhinery.

Fig: 6. Elevalion.

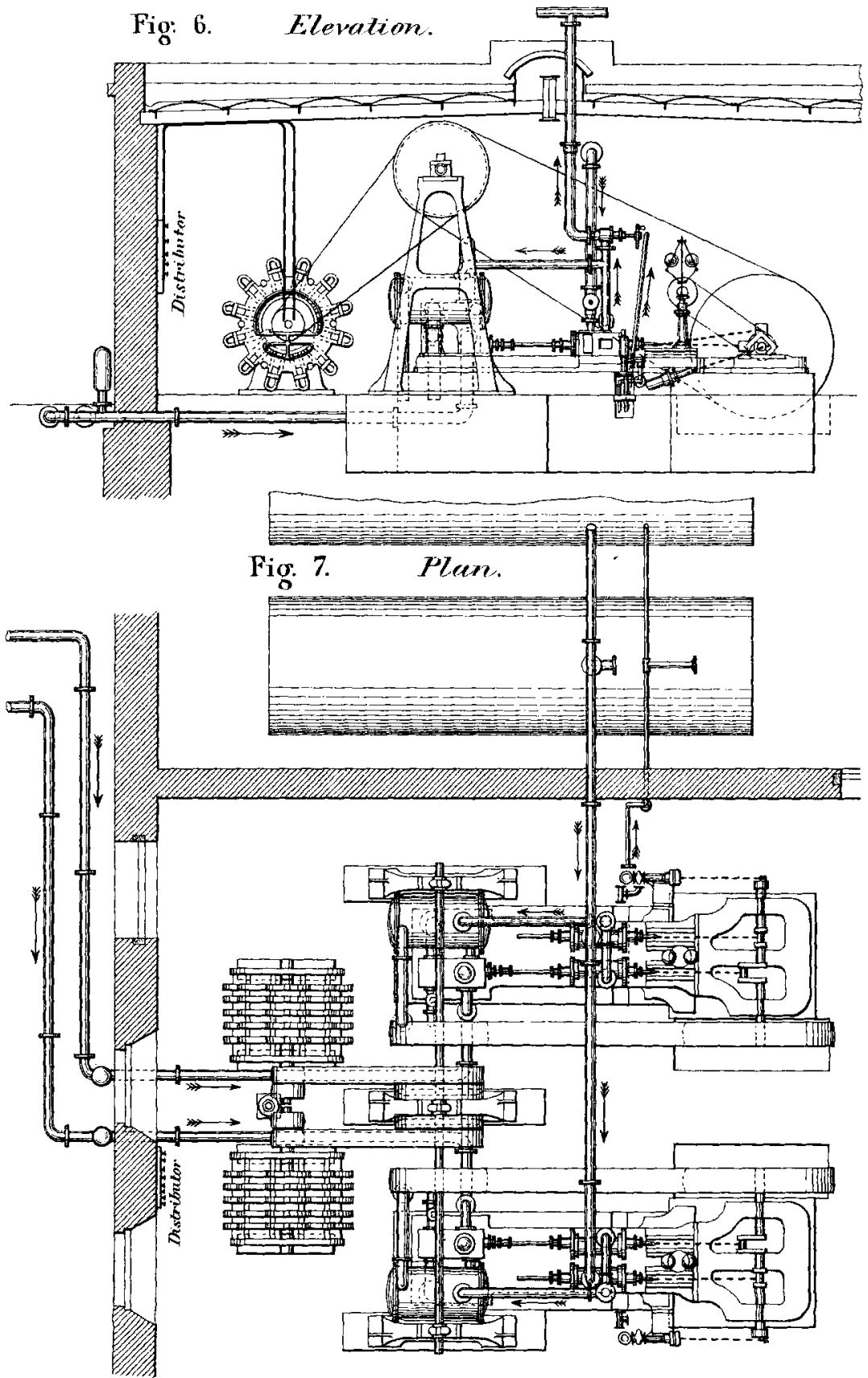

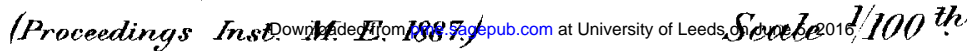


ELECTRIC LIGHTHOUSE.

Plate 64.

\section{Dioptric Apparatus.}

Fig. 8. Vertical Section.
a '. 20bove horizon
b 3 below horizon
$f$ 5 below horizon

tabove horizon a

30 below horizon $b$

$5^{\circ}$ below horizon $f$

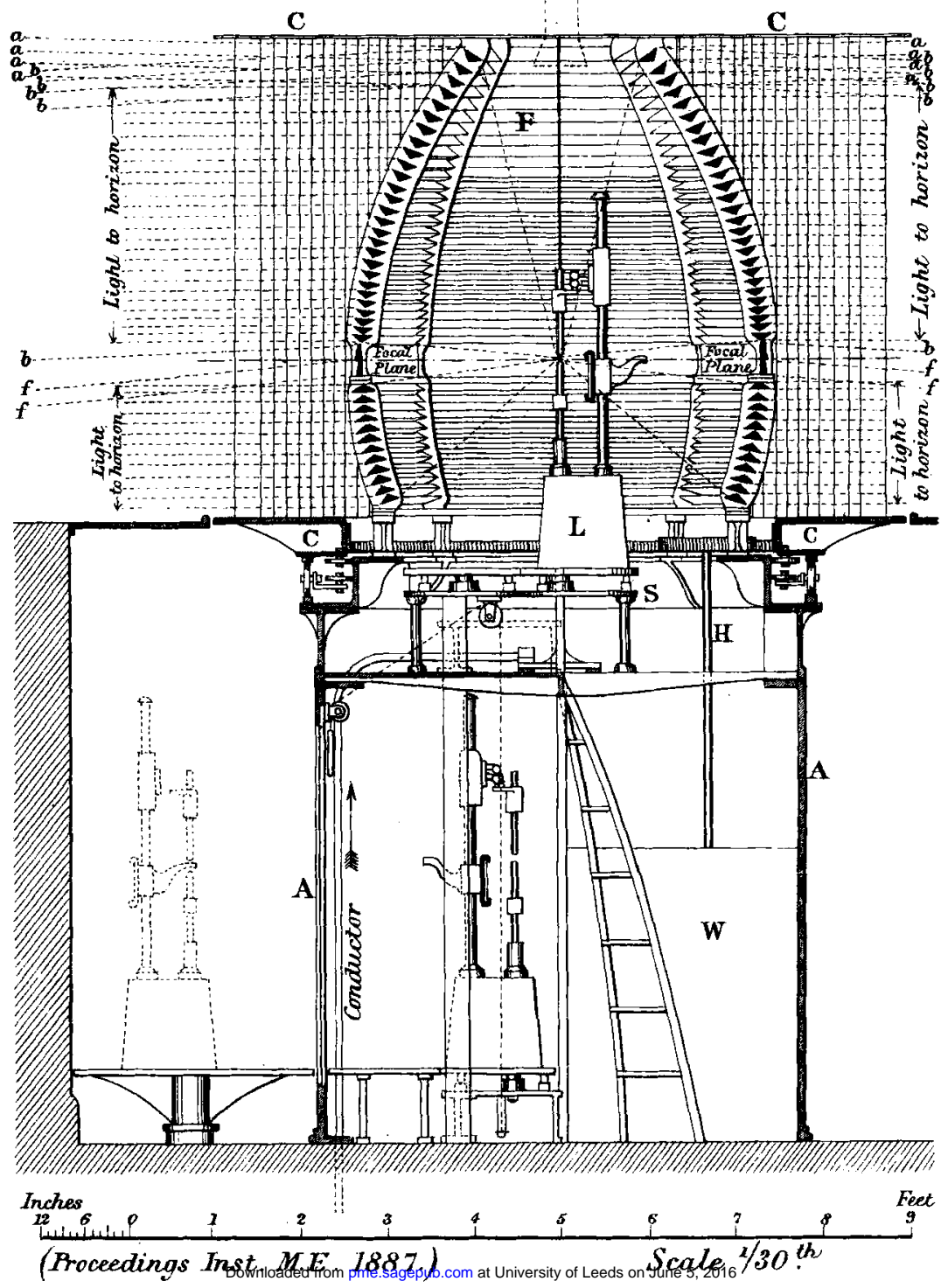


ELECTRIC LIGHTHOUSE.

Plate 65.

\section{Dioptric Apparatus.}

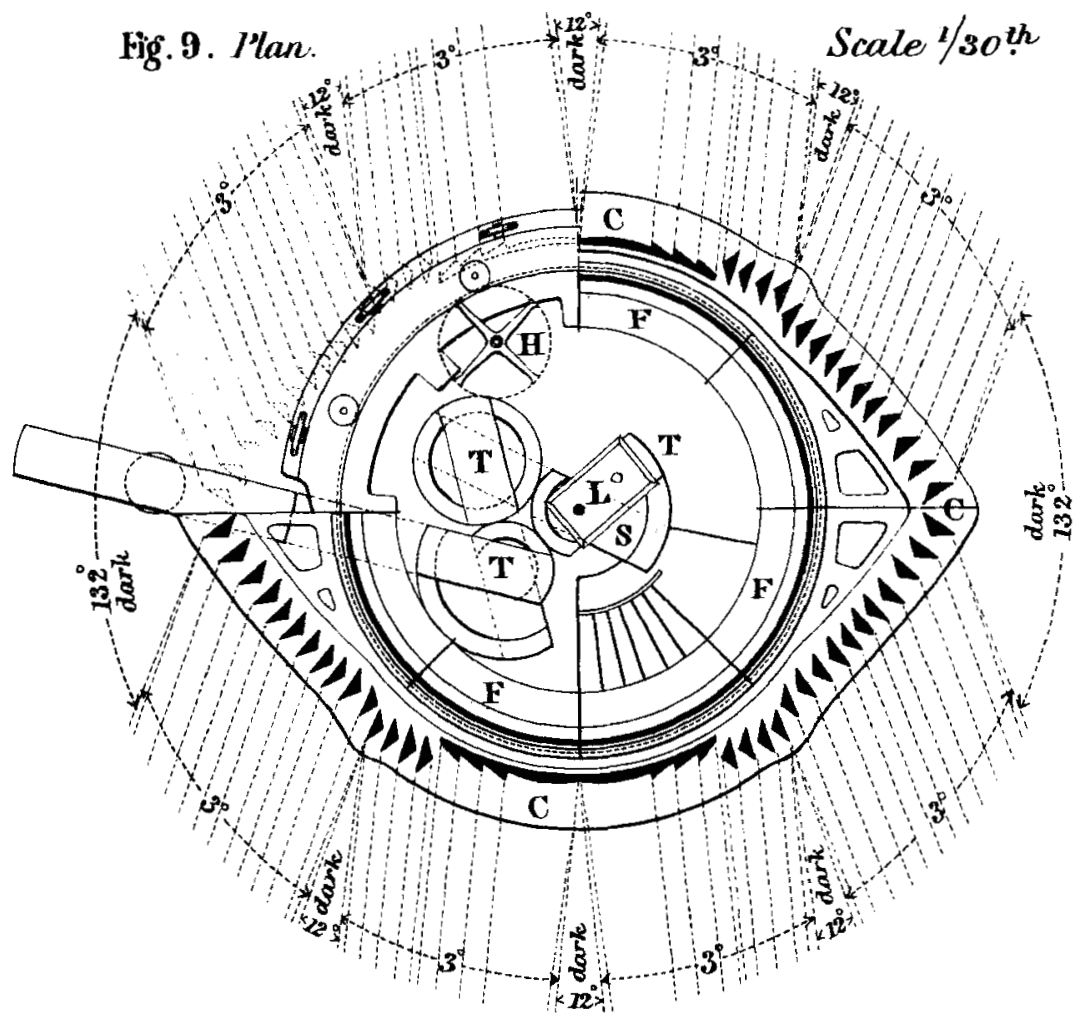

Wall carrying Copper Conductors.

Fig. 10. Side Elevation.

Fig. 11.

Transverse Section.
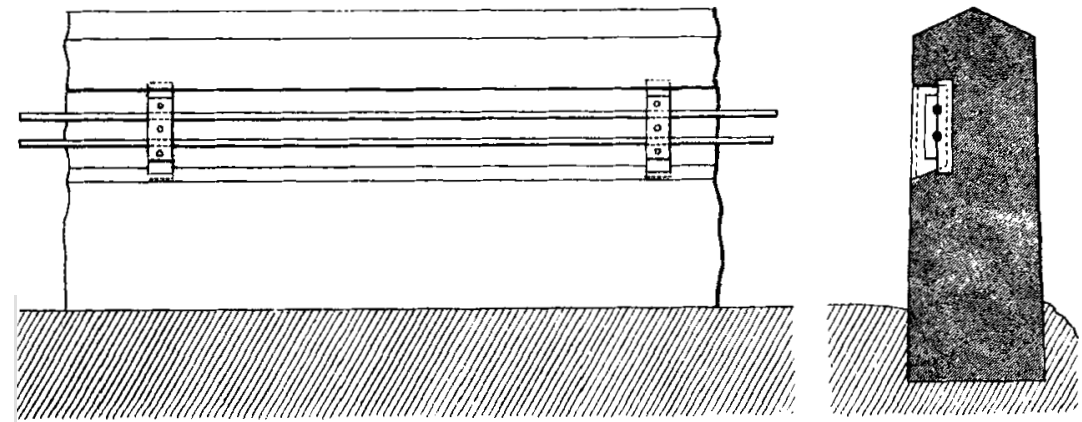

Inethes

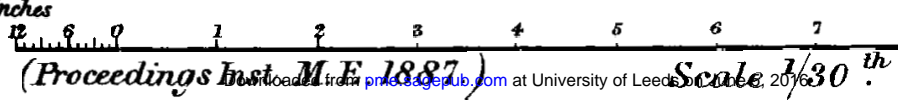

Feet 


\section{ELECTRIC LIGHTHOUSE. Plate 66 .}

Carbons for Are light.

\section{Cylindrical Carbons $50 \mathrm{~mm}$. diameter.}

Continumus Current.

Fig. 12.

Elevation. Vertical Section.
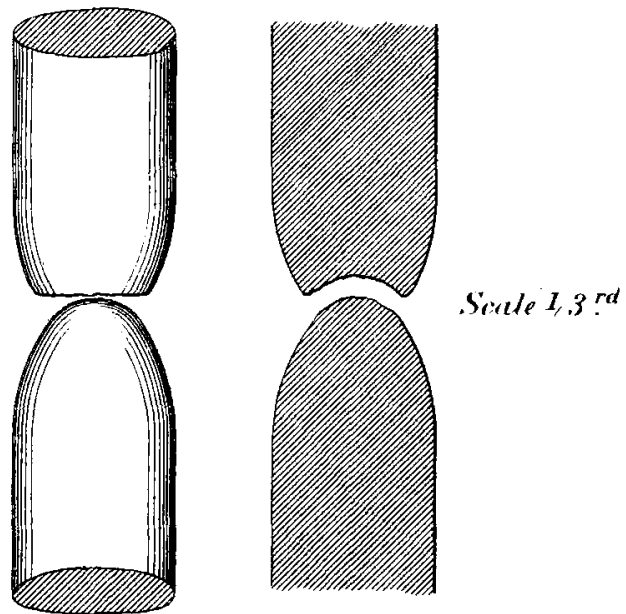
Alternating Current.

Fig: 14.

Fig: 15. Elevation. Vertical Section.
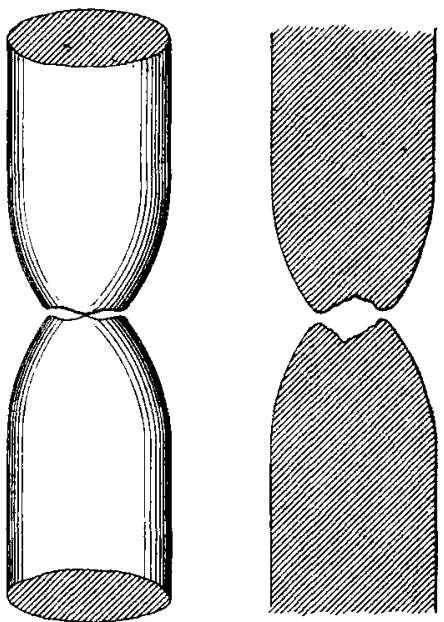

Fluted Carbons $50 \mathrm{~mm}$. diameter. Alternating Current.

Fig: 18. Transverse Section at $\mathrm{XX}$.

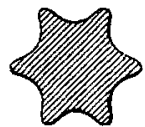

Fig 19.

Transverse Section

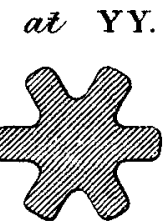

Fig: 16. Elevation
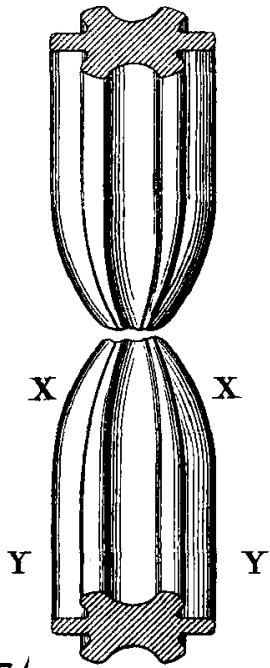

Fig 17. Vertical Section.
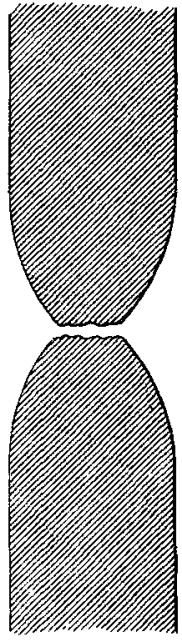

S'cale $1 / 3$ rd 